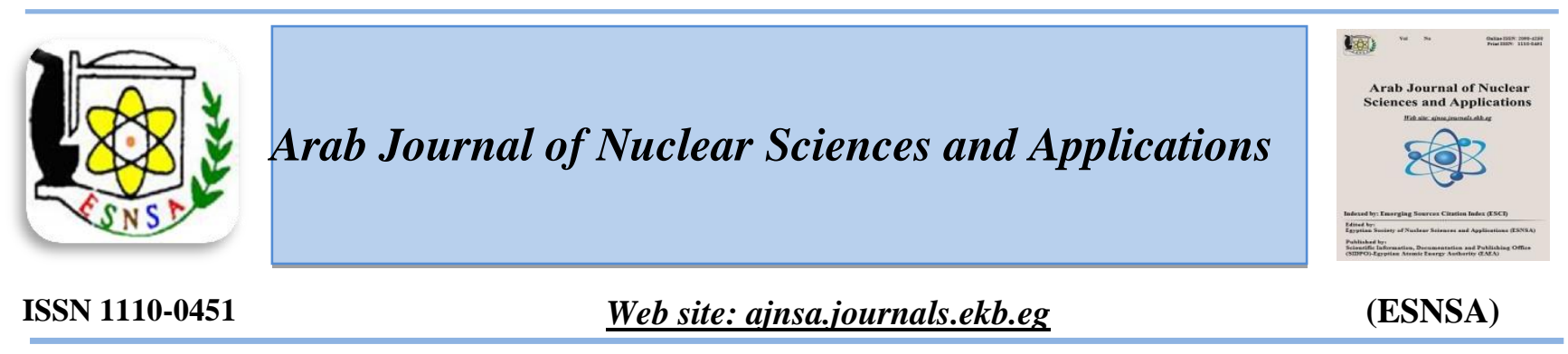

\title{
Effect of Addition of GO Nanoparticles on the Tensile Properties and Deformation Temperature of Sn-3.5Ag-0.7Cu Lead Free Solder Alloy
}

\author{
M.Y. Salem \\ Physics Department, Faculty of Science, New Valley, Assuit University, El-Kharga, Egypt
}

Received $18^{\text {th }}$ Feb. 2018 The advantage of lead-liberated welding is the melting point of Sn-Ag-Cu (SAC) alloys in the Sn-rich Accepted $7^{\text {th }}$ Dec. 2018 alloy. Nanoparticles welding which requires lowering melting point near the Sn-Pb eutectic point is getting a growing interest. Recently, the phase persistence of nanoparticles has been the project of massiveness of academic and experiential investigations. In this study, graphene nanoparticles (GNPa) with 0.3 percentages wt. $\%$ were successfully added into $\mathrm{Sn}-3.5 \mathrm{Ag}-0.7 \mathrm{Cu}$ lead-free solder. The effects of graphene nanoparticles (GNPa) on the microstructure, tensile properties, wettability, corrosion resistance, and hardness were subsequently investigated. The results show that graphene nanoparticles (GNPa) refine the microstructure with different features and enhance the wettability efficiently. Stressstrain tests show that the combined solder containing $0.3 \mathrm{wt}$ graphene nanoparticles (GNPa) exhibits about $15 \%$ and $25 \%$ enhancement in tensile strength and hardness, respectively. In addition, the total

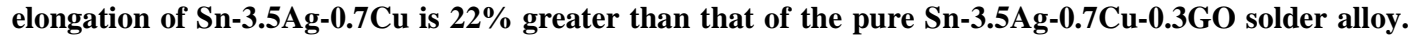
The enhancing mechanism of $0.3 \mathrm{GO}$ on the achievement of combined samples is also studied. Stress strain experiments were inspected under different five strain rates ranging from $5.4 \times 10^{-5} \mathrm{~S}^{-1}$ to $2.9 \times 10^{-3}$ $\mathrm{S}^{-1}$ and different five temperatures extended from R.T. (298K) to $383 \mathrm{~K}$ for two alloys. The activation enthalpy suggests that the dominant mechanism is the grain bounding diffusion (GBD). Also, X-ray diffraction examination display the permanence of both $\beta$-Sn rich phase and the intermetallic compound $\mathrm{Ag}_{3} \mathrm{Sn}$ and very little particles or residue from the intermetallic composition $\gamma$-In $\mathrm{Sn}_{4}$.

Keywords:Nanoparticles /Tensile properties / Free solder alloy

\section{Introduction}

The recent microelectronic industry, need solder; which are collective and plays an important function in suggestion electronic connection and mechanical backing for the precision of integrated circuits, which directly influences the realization of electronic application [1,2]. Sn-Ag-Cu alloys welder sample was excessively utilized through the latter days. The lead-free solder has been developed currently due to the harmful impact on the environment and human health [3-5].

Significant studies has been concentrated on the composition of $\mathrm{Sn}-\mathrm{Ag}-\mathrm{Cu} \quad(\mathrm{SAC})$ [6-9] nanoparticles is appropriate and nominee for production of lead-free solders because of the lessening of melting degree. As a matter of reality, melting point depression in nanosolders was the main interest of most of these investigations, since the melting point of eutectic SAC bulk alloys is about $217{ }^{\circ} \mathrm{C}$, about $34{ }^{\circ} \mathrm{C}$ higher than that of the of the conventional eutectic tin-37\% lead alloy [10].

Many mechanisms such as the GibbsThomson, has been before suggested to characterize the size reliance of the melting degree of nano-sized particles [11]. It is supposed that, as 
the melting is started by persistent vibrational lattice sensitivity on the solid surface, nanoparticles with considerable surfaces will miss their stability at reduced temperature than bulk. The melting point depression for Graphene Oxide (GO) nano may be qualified for instance in a conventional thermodynamic approximation by the Gibbs-Thomson equation [12], as follows:

$$
T_{m}^{\text {Nano }}(r)=T_{m}^{\text {bulk }}-\frac{2\left(T_{m}^{\text {bulk }}+273.15\right) \sigma_{\mathrm{s}} \mathrm{l}}{\Delta \mathrm{H}_{f}^{\text {bulk }} \rho_{\mathrm{s}} \mathrm{r}}
$$

Where $\sigma_{s l}$ is the solid-liquid interfacial energy $\left(\sim 820 \mathrm{~J} / \mathrm{cm}^{2}\right), \rho_{s}$ is the solid phase density of bulk alloy $\left(7.39 \mathrm{~g} / \mathrm{cm}^{3}\right)$ and, $\Delta \mathrm{H}_{f}^{\text {bulk }}$ is the latent heat of fusion of the bulk alloy $(\sim 67 \mathrm{~J} / \mathrm{g})$ for the eutectic SAC composition [13], $T$ is fusion point. Other models prophesy a basically identical relationship as the Gibbs-Thomson equation, where $T_{m}$ changes linearly with the reciprocal radius.

The CALPHAD (Computer Calculation of Phase Diagrams)-type thermodynamic characterization of nanoparticles samples is a massive contrivance for portend the phase diagram of nanoparticles about to or higher than $10 \mathrm{~nm}$ in diameter [14]. For the minimum particle size in the domain of little separated atoms, a bottom-up calculation such as molecular dynamics become true [15]. The CALPHAD-type for a nanoparticles sample process was first studied by Park and Lee [16].

For an identical melting system containing intermetallic particles like the Sn-Ag system, Sim and Lee [14] achieved latterly a regular survey, where the base Gibbs free energy of the stoichiometric compound $\left(\mathrm{Ag}_{3} \mathrm{Sn}\right)$ was estimated based on the presence data for the surface pull of $\mathrm{Ag}_{3} \mathrm{Sn}$.

The ternary SAC eutectic alloy solder has different characteristic up the binary SA eutectic solder, due to its lower eutectic point, decelerate increase of the intermetallic category at the interface, excess strength, and minimize moistening angle $[2,17]$. Since the melting point of the ternary SAC alloys in the Sn-rich nook are of advantage for lead-free soldering, and many experimental researches on the phase deepness of SAC nanoparticles have been completed, the CALPHAD-type thermodynamic design of the binary SA nanosystem has been elongated to the ternary SAC nano-system.

In order to improve the performance of Sn$3.5 \mathrm{Ag}-0.7 \mathrm{Cu}$ solder alloy, introducing minor of nanomaterials $0.3 \mathrm{GO}$ as reinforcing phases into the conventional solder alloy $[2,18-20]$ is proved to be an effective and feasible method. Shen et. al. [21] reported that the nanoaddition could promote the hardening and creep resistance of alloys. Shen et. al., [22] found that the addition of nano refine and improve structure and mechanical properties. Yang et. al. [23] investigated the solder alloy enriched by Nano and point out the ductility and tensile strength were modified by bridging influence and pregnancy move. Graphene nanosheets (GNSs) are well known for its high thermal conductivity, excellent electronic properties and great mechanical strength [24-26]. Corresponding wettability and tensile strength improvement [27] in $\mathrm{Sn}-\mathrm{Ag}-\mathrm{Cu}$ solder alloy reinforced with the addition of Graphene nanosheets (GNSs) were obtained.

By the increment of Graphene nanosheets (GNSs), the abrasion resistance can be increased and the construction of inter metallic compounds (IMCs) enable as well be penned in the solder form during the consequence of $\mathrm{Xu}$ et. al; [28, 29]. In the study of Huetal [30], the increased hardness and the lower mounting rate of IMCs were gained by the strengthening techniques of the introduced grapheme in the $\mathrm{Sn}_{8} \mathrm{Zn}_{3} \mathrm{Bi}$ solder alloy. Maetal [31] found that the creep resistance [32] and ultimate tensile strength were enhanced significantly by addition of Graphene nanosheets (GNSs). Moreover, Pengand Deng [2,33] investigated the Graphene composite solder by finite element simulation and discovered $192 \%$ enhancement in shear modulus with $1.0 \mathrm{wt} . \%$ grapheme addition.

Arab J. Nucl. Sci. \& Applic. Vol. 52, No. 1 (2019) 


\section{Experimental Procedures}

The Graphene Oxide (GO) (99.99\%purity) with an average particle size of $10 \mu \mathrm{m}$ and density of 3.21 $\mathrm{gm} / \mathrm{cm}^{3}$ was used as powder substance; GO powders had a random morphology, it was fabricated by high energy ball milling technique, as described elsewhere [34, 35]. High purity GO powder was used as starting materials. The chemical compositions of two used solder alloys are $\mathrm{Sn}-3.5 \mathrm{Ag}-0.7 \mathrm{Cu}$, and $\mathrm{Sn}-3.5 \mathrm{Ag}-0.7 \mathrm{Cu}-0.3 \mathrm{GO}$, the $\mathrm{Sn}-3.5 \mathrm{Ag}-0.7 \mathrm{Cu}$ (SAC) solder was prepared from bulk $\mathrm{Sn}, \mathrm{Ag}$ and $\mathrm{Cu}$ rods (all with $4 \mathrm{~N}$ purity), the $\mathrm{Sn}-3.5 \mathrm{Ag}-0.7 \mathrm{Cu}-0.3 \mathrm{GO}$ composite solders were prepared by mechanically mixing the GO nanoparticles with $\mathrm{Sn}-3.5 \mathrm{Ag}-0.7 \mathrm{Cu}-0.3 \mathrm{GO}$ alloy melt of the GO particles into the melt for 40 min to fixed a similar allocation of the growing of particles as seen in Table (1).

During preparation, the pre-weighted ingot (Sn3.5Ag-0.7Cu-0.3GO) and $\mathrm{GO}$ particles were first put into an $\mathrm{Al}_{2} \mathrm{O}_{3}$ crucible and was completed in a vacuum arc furnace under the protection of high purity argon atmosphere at $450{ }^{\circ} \mathrm{C}$ for about 120 min. The blended particulates were pressed to predestine the sample with suitable dimensions. The powder particle was designed by increasing a little amount of powder in a resin followed by conventional grinding and polishing methods; to obtain an identical structure during the ingots, the samples was re-melted three times to product rodlike samples with a diameter of about $0.8 \mathrm{~mm}$ and $5 \mathrm{~cm}$ standard length. The sample was resigned at $25{ }^{\circ} \mathrm{C}$ for 168 hour before testing. More details of composite alloys preparation are described elsewhere [36-39]. This operation is declaration to permit a small amount of grain growth and grain stabilization to occur [40, 41]. The samples were tested at different five temperatures ranging from R.T. (298K) to $383 \mathrm{~K}$ for the two alloys under different strain rate ranging from $5.4 \times 10^{-5} \mathrm{~S}^{-1}$ to $2.9 \times 10^{-3} \mathrm{~S}^{-1}$, using a conventional type creep machine [41]. The chemical compositions of the experimental alloys are represented in Table (1) and in Fig. (1); used Energy-dispersive X-ray spectroscopy (EDX) used in this investigation. The accuracy of temperature measurement is of the order \pm 1 K. Strain measurements were done with an accuracy of $\pm 1 \times 10^{-4}$. A solution of $2 \% \mathrm{HCl}, 3 \%$ $\mathrm{HNO}_{3}$ and $95 \%$ (vol.\%) ethyl alcohol was prepared and used to etch the samples.

$\begin{aligned} & \text { Table (1): Chemical composition of the solder } \\
& \text { alloys studied(wt. \%). }\end{aligned}$
\begin{tabular}{lllll}
\hline Solder alloy & GO & $\mathrm{Sn}$ & $\mathrm{Ag}$ & $\mathrm{Cu}$ \\
\hline Sn-3.5Ag-0.7Cu & - & 96. & 3.5 & 0.7 \\
Sn-3.5Ag-0.7Cu- & 0.3 & 95. & 3.5 & 0.7 \\
\hline
\end{tabular}

\section{Results and Discussion}

Energy-dispersive $X$-ray spectroscopy (EDX), and X-ray diffraction (XRD) of tested samples.

EDX, pattern for the tested alloys is symbolized in Fig. (1). Using EDX analysis, the percentage of $\mathrm{Sn}, \mathrm{Ag}$, and $\mathrm{Cu}$ are found similar to that value in Table (1). Fig. (2a) and b describe the XRD chart of the two solders. The acquired phases are characterized by draw an analogy between the Bragg peaks and the ASTM standards. A ponderous peak of $\beta$-Sn rich phase was constructed to be slightly diminutive with the extension of $\mathrm{Cu}$, because of the construction of $\mathrm{Cu}_{6} \mathrm{Sn}_{5}$ phases aside from little peaks of $\mathrm{Ag}_{3} \mathrm{Sn}$. It is well recognized that, the disbanded $\mathrm{Sn}, \mathrm{Ag}$ and $\mathrm{Cu}$ are condensed by presence of $\mathrm{Ag}_{3} \mathrm{Sn}$; the $\mathrm{Ag}_{3} \mathrm{Sn}$ phase was found in the XRD pattern indicating the successful alloying of $\mathrm{Sn}$ and $\mathrm{Ag}$ after the melting point. The $\mathrm{Cu}_{6} \mathrm{Sn}_{5}$ IMCs in the tin matrix during solubility were owing to the mixing of $\mathrm{Sn}$ and Cupper $[42,43]$. Though, the intensity of GO composite is comparatively small, the major peaks of GO were exposed in Fig. (2b).

Microstructure change with addition of $\mathrm{Ag}, \mathrm{Cu}$, and $G O$

The SEM photograph are seen in Fig. (3a) Sn$3.5 \mathrm{Ag}-0.7 \mathrm{Cu}$ alloy microstructure composed of light grey areas of $\mathrm{Ag}_{3} \mathrm{Sn}$ and dark network-like eutectic regions of $\beta$-Sn grain boundaries, and grey particles represented $\mathrm{Cu}_{6} \mathrm{Sn}_{5}$. In Fig. (3b), the suitable density of GO in the ternary solder was construct to upgrade the morphology, mechanical properties and are capable to refine the grain size, the $\mathrm{Ag}_{3} \mathrm{Sn}$ IMCs, and the $\mathrm{Cu}_{6} \mathrm{Sn}_{5}$ perhaps doing as varied nucleation sites for $\beta-\mathrm{Sn}$ 
dendrites upon solidification and also white GO phase. It was explain that, the smooth in grain size originate from the existence of reinforcing GO samples which behave as pinners' to grain boundaries [37, 39]. This supervision may be characterized by the theory of diversified nucleation and the theory of adsorption of the surface active material. Therefore, the excess of adsorption of elements or oxides (GO) could decreasing the surface energy and reducing the dimension of IMCs of GO solder. Then, the least $\beta$-Sn grains as well; GO at the intermediate borders could be diffusion owing to the bounded solid solubility of GO in solder matrix. Thus, it is prophesy while combining GO is one of accepted nano-solder [44-45].

\section{Mechanical properties}

\section{Tensile properties}

The effect of GO Nanoparticles supplement on the mechanical properties of $\mathrm{Sn}-3.5 \mathrm{Ag}-0.7 \mathrm{Cu}$ samples at Room Temperature R.T. (298K), 333K, and 383 $\mathrm{K}$ and different strain rates were illustrated the relation of stress-strain curves as seen in Figs. (45) and Table (2). It was spotted that, the stress scales transferred across higher values with rising the strain rate and/or lessening the testing temperature. Significant of observation is that, the flow stress permanently lowered with growing elongation and plain solder alloy exhibited higher ductility than composite solder alloy. Usually, through plastic deformation solder alloys undergo simultaneous work hardening and dynamic recovery which have opposite effects on the plastic decreates additional dislocation forests during solder lattice space particularly at minimize testing temperature [38, 39]. Moreover, with increasing the testing temperature the dislocation annihilation takes place more quickly than dislocation propagation that is weakening the hardening. It is shown that $\mathrm{Sn}-3.5 \mathrm{Ag}-0.7 \mathrm{Cu}-0.3 \mathrm{GO}$ is more strengthening than $\mathrm{Sn}-3.5 \mathrm{Ag}-0.7 \mathrm{Cu}$ i.e. second alloys $\mathrm{Sn}-3.5 \mathrm{Ag}-0.7 \mathrm{Cu}$ are extra expansion than the GO Nanoparticles solders.

At constant strain rate equal $3.0 \times 10^{-4} \mathrm{~s}^{-1}$ and different five testing temperature the effect $\mathrm{GO}$ additions of $\mathrm{Sn}-3.5 \mathrm{Ag}-0.7 \mathrm{Cu}$; the tensile behavior were explained in Fig. (5) c,d. It is shown that the
GO samples need more stress to reach the same strain, this mean GO samples are more in tensile strength by about $15 \%$.

Table (2): Tensile testing condition

\begin{tabular}{lll}
\hline Solder alloy & Strain Rate $\left(\mathrm{S}^{-1}\right)$ & Temp.(K) \\
\hline Sn-3.5Ag-0.7Cu & $5.4 \times 10-5$ & 298 \\
& $3 \times 10-4$ & 313 \\
Sn-3.5Ag-0.7Cu-0.3GO & $1.15 \times 10-3$ & 333 \\
& $2.9 \times 10-3$ & 358 \\
& & 383 \\
\hline
\end{tabular}

Influence of temperature and $\varepsilon$. Young's modulus $(\mathrm{y})$, yield stress $(\sigma \mathrm{y})$, and $\sigma \mathrm{f}$.

Fig. $(6 a, b)$ lists the variation of Young's modulus (Y) with strain rate at different working temperature for $\mathrm{Sn}-3.5 \mathrm{Ag}-0.7 \mathrm{Cu}$ and $\mathrm{Sn}-3.5 \mathrm{Ag}$ $0.7 \mathrm{Cu}-0.3 \mathrm{GO}$. It is clear that Young's modulus (Y) for composite samples is higher than that of plain samples. The Variation of yield stress $(\sigma y)$ with strain rate at different working temperature for Sn$3.5 \mathrm{Ag}-0.7 \mathrm{Cu}$, and $\mathrm{Sn}-3.5 \mathrm{Ag}-0.7 \mathrm{Cu}-0.3 \mathrm{GO}$ is shown in Fig. $(6-c, b)$; it is clear the yield stress $(\sigma y)$ for GO solders is more than that of plain samples. It is displayed that at the same testing temperature, raising the strain rate leads to altitude amounts of yield strength. The relation between the fracture strength (breaking strength) $\sigma f$ and strain rate at different working temperature for Sn$3.5 \mathrm{Ag}-0.7 \mathrm{Cu}-0.3 \mathrm{GO}$ and $\mathrm{Sn}-3.5 \mathrm{Ag}-0.7 \mathrm{Cu}$ is illustrated in Fig. (7a, b); but in Fig. $(7 c, d)$ the comparison the ultimate tensile stress (UTS) with strain rate for $\mathrm{Sn}-3.5 \mathrm{Ag}-0.7 \mathrm{Cu}$ and $\mathrm{Sn}-3.5 \mathrm{Ag}$ $0.7 \mathrm{Cu}-0.3 \mathrm{GO}$ is represented. It is evident that fracture strength $(\sigma \mathrm{f})$ for $\mathrm{GO}$ nanosolders is more than that of other solders; the strain rate is directly proportional to fracture strength. The strain rate reliance of the total elongation $\varepsilon_{\mathrm{t}}$ was constructing to follow an experimental equation of the form [46]:

$\varepsilon_{\mathrm{t}}=\mathrm{A} \exp \left(-\lambda \varepsilon^{*}\right)$

Where $\mathrm{A}$ and $\lambda$ are fixed constant depending on the tensile test situation

Strain rate and temperature dependence of the ultimate tensile stress (UTS).

Arab J. Nucl. Sci. \& Applic. Vol. 52, No. 1 (2019) 
Ultimate tensile stress (UTS) values of $\mathrm{Sn}-3.5 \mathrm{Ag}$ $0.7 \mathrm{Cu}$, and $\mathrm{Sn}-3.5 \mathrm{Ag}-0.7 \mathrm{Cu}-0.3 \mathrm{GO}$ is inversely proportional with and temperature and directly with strain rate as demonstrated in Fig. (7 c, d). It is obvious that the value of (UTS) for nano samples is higher than that of ternary samples by about $11 \%$ as shown in Table ( 3 and 4 ). From Fig. $(8-a, b)$; it is obvious that the total elongation in the two alloys is inversely proportional with strain rate and temperature at all strain rates; in Fig. (8a, b) $\mathrm{Sn}-3.5 \mathrm{Ag}-0.7 \mathrm{Cu}$ alloy has values of total elongation $\left(\varepsilon_{t}\right)$ higher than that of GO particles by about $25 \%$; due to softest nature of this alloy. This difference in the rapport between tensile elongation as characterization of strain rate and temperature appears to concern on the difference in the microstructure of the alloys. It is renowned that the tensile coefficient, the yield stress, fracture strength, and the total elongation of affected by the alteration of the strain rate and temperature as represented in table in Table $(3,4)$.

It is clear that $\mathrm{SR}\left(\varepsilon^{*}\right)$ is directly proportional to the UTS in two tested samples; this is owing to rising strain rate is followed by rising in the dislocation density. As these dislocations shift they will complicated. It is then more complicated for else dislocations to elapse through the material, particularly at the minimized tested temperatures. The UTS value of GO nano sample presented is ultimate than $\mathrm{Sn}-3.5 \mathrm{Ag}-0.7 \mathrm{Cu}$ sample. The higher values of the UTS in the GO alloy may be due to the refinement and uniform distribution of the intermetallic $\mathrm{Ag}_{3} \mathrm{Sn}$, and $\mathrm{Cu}_{6} \mathrm{Sn}_{5}$ particles, it appear to supply a maximal measure of dispersion strengthening due to the finer particle size in the GO alloy compared to the Sn-3.5Ag-0.7 Cu alloy.

Table (3): strain rate on tensile parameters of $\mathrm{Sn}-3.5 \mathrm{Ag}-$ $0.7 \mathrm{Cu}$

\begin{tabular}{lllllll}
\hline Temp. K & $\mathrm{Y}$ & $\sigma_{\mathrm{y}}$ & $\sigma_{\mathrm{f}}$ & $\mathrm{UTS}$ & $\varepsilon_{\mathrm{f}}$ & $\varepsilon_{\mathrm{t}} \%$ \\
\hline 298 & 3700 & 45 & 57 & 58 & 0.85 & 107 \\
313 & 3520 & 41 & 48 & 48 & 0.79 & 102 \\
333 & 3464 & 38 & 45 & 43 & 0.75 & 99 \\
358 & 3210 & 31 & 36 & 35 & 0.73 & 83 \\
383 & 3003 & 23 & 25 & 27 & 0.71 & 78 \\
\hline
\end{tabular}

Table (4): strain rate on tensile parameters of $\mathrm{Sn}-3.5 \mathrm{Ag}$ $0.7 \mathrm{Cu}-0.3 \mathrm{GO}$

\begin{tabular}{lllllll}
\hline Temp. K & $\mathrm{Y}$ & $\sigma_{\mathrm{y}}$ & $\sigma_{\mathrm{f}}$ & UTS & $\varepsilon_{\mathrm{f}}$ & $\varepsilon_{\mathrm{t}} \%$ \\
\hline 298 & 4249 & 57 & 62 & 64 & 0.80 & 87 \\
313 & 3930 & 44 & 53 & 55 & 0.76 & 75 \\
333 & 3814 & 42 & 48 & 50 & 0.73 & 70 \\
358 & 3654 & 36 & 41 & 41 & 0.70 & 62 \\
383 & 3527 & 33 & 35 & 34 & 0.68 & 50 \\
\hline
\end{tabular}

We can sight that, strain rate is inversely proportional with $\left(\varepsilon_{f}\right)$ as ordinance in Fig. $(8 \mathrm{c}, \mathrm{d})$. It was celebrated that the yield stress $\left(\sigma_{\mathrm{y}}\right)$ and UTS are highly influenced by the distinction of strain

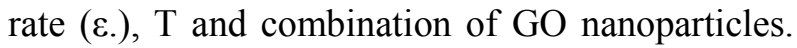
The value of $\sigma_{\mathrm{y}}$ and UTS is inversely comparative to the testing temperature and/or lowering the strain rate. These alterations can be known by regarding the plastic variations as thermally activated process and average conditioned of stress-assisted. Therefore, the dislocations have extra movement if thermal energy is raised and could dominate the barrier through $\beta$-Sn matrix $[47,48]$. Hence, raising the temperature elevates the configuration of collection dislocation network into simple one. Therefore, at elevation strain rate, the $\sigma_{\mathrm{y}}$ and UTS are enhancement due to bounded time of the dislocation movement which produces heavy pinning locations and excess harden defects.

The reinforcement mechanism of the composite solder could be characterized in terms of harden GO nanoparticles and finer IMCs which spread within eutectic regions. They perform as defined centres which prevent the movement of dislocation that focused surrounded grain boundaries [49]. Furthermore, more disorder has been created with various slipping planes and various tendencies. Therefore, identical sign of consecutive dislocation would repel and collect in the domains of $\beta-\mathrm{Sn}$ grains. In extension to, the enormous slipping dislocations behave as tough obstructed web which is believe as one of the purpose for the strengthen mechanism of GO nanoparticles solder.

Zener pinning equation [50] was used to calculate the pinning stress that prevent the growth of $\beta-\mathrm{Sn}$ grains due to presence of finer IMCs and GO nanoparticles.

$\sigma_{\mathrm{p}}=\frac{3 \mathrm{f} \gamma_{G B}}{\mathrm{~d}}$ 
where $\mathrm{t}$ is the particle volume fraction, $\mathrm{d}$ is the particle radius and $\gamma \mathrm{GB}$ is the grain boundary energy of $\mathrm{Sn}\left(\gamma_{\mathrm{GB}}{ }^{1 / 40.425} \mathrm{~J} / \mathrm{m}^{2}\right)$ [51]. Thedefined stress values $\sigma p$ of $\mathrm{Sn}-3.5 \mathrm{Ag}-0.7 \mathrm{Cu}-0.3 \mathrm{GO}$ alloy are major than ternary solder alloy due to the presence of finer IMCs.

It is also interesting to note that the increased ductility of $\mathrm{Sn}-3.5 \mathrm{Ag}-0.7 \mathrm{Cu}$ than GO alloy is completed without sacrificing the mechanistic intensity. However, after the stress grade rise up to yield strength of the solder alloys, the strain hardening, instead of strain softening, has occurred in all the as-solidified solder alloys, which may consolidate the UTS and yield strength solders samples [52]. Since the distortion resistance of samples was defined crucial important mechanical property, a good deformation resistance suggests great plastic region. Compared with the $\mathrm{Sn}-3.5 \mathrm{Ag}$ $0.7 \mathrm{Cu}$ alloy and $\mathrm{Sn}-3.5 \mathrm{Ag}-0.7 \mathrm{Cu}-0.3 \mathrm{GO}$ alloy solders, which have a small misrepresentation resistance, a superior misrepresentation resistance and elongated ductile region of $\mathrm{Sn}-3.5 \mathrm{Ag}-0.7 \mathrm{Cu}$ alloy would insure this solder to become one of prefer for replacing the $\mathrm{Sn}-3.5 \mathrm{Ag}-0.7 \mathrm{Cu}-0.3 \mathrm{GO}$ solder in microelectronic packaging and interconnecting. The immovability to necking has been modified because of the high interface formed between Cu6Sn5 IMCs and the $\beta-S n$ matrix, which in turn enhanced both ultimate tensile stresses. While, the $\mathrm{Ag} 3 \mathrm{Sn}$ IMCs particles formed in the $\mathrm{Sn}-3.5 \mathrm{Ag}-0.7 \mathrm{Cu}-0.3 \mathrm{GO}$ alloy can strongly enhance the ultimate tensile stress UTS of this alloy because of lower elastic modulus of these IMCs inside the solder matrix. These results are consistent with the previous finding that the Cu6Sn5 often exhibits a larger elastic modulus than Ag3Sn IMCs [52].

\section{Stress exponents and activation energy}

Tensile misrepresentation mechanisms are specified by the values of $\mathrm{n}$ and the activation energy Q. In fact, distortion of polycrystalline materials at temperatures over $0.5 \mathrm{Tm}$ can happen by various deformation mechanisms, connected with various stress exponent amount. Propagation creep is related with $\mathrm{n}$ values nearly 1 . The connection of stress-strain of Sn-based solder alloys is generally illustrated by the power-law of the kind [53-56]

$\varepsilon^{\cdot}=\mathrm{A} \sigma^{\mathrm{n}} \exp (-\mathrm{Q} / \mathrm{RT})$

The activation energy may be estimated from the connection between $\ln$ (fracture strain $\varepsilon_{f}$ ) with $1000 / T$ at several working temperature for the two alloys as demonstrated in Fig. ( $9 \mathrm{a}, \mathrm{b}$ ). The value of activation energy with temperature for solders is demonstrated in Fig. (9c).

\section{Effect of temperature on stress exponent.}

Fig. (10a) and b illustrated the relation between log (strain rate $\varepsilon$.) with $\log (\sigma \mathrm{UTS})$ for both alloys at different temperatures. An evident linear relationship is spotted; this signifies that the relationship obeys [38];

$\varepsilon=\mathrm{C} \sigma^{\mathrm{n}}$

Where $\sigma$ is UTS, $\mathrm{n}$ is the stress exponent, and $\mathrm{C}$ is a constant for certain sample. The $\mathrm{n}$ values estimated from slope of two-logarithmic connection. Fig. (10c) abbreviated the gained $n$ values for solders. These results illustrate that, then values decrease with increasing temperature; the value on $\mathrm{n}$ is around 2.39: 3.12 and from 3.44: 3.75 for two samples; respectively. Furthermore, the estimated of $n$ quickly reducing for plain solder but remain comparatively stable for composite at fixed tested temperature. In fact; the distinction of $n$ values with temperature is assigned to the rockiness of the microstructure of GO solder.

Mechanical alloying mechanism exemplifies to be a perfect way to synthesize nanocomposites in a different of systems. The ultimate apparent characteristic of the Mechanical alloying (MA) mechanism is that a symmetrical dispersion can be carried out by optimizing the processing contract. The elastic modules can be associated well with the additions of GO reinforcements in to the Sn matrix. The GO or ( $\mathrm{ZnO})$ advise to be favourable in that it gave good aggregation of slightly higher stiffer nature and fine particle size than Sn matrix, which was possible because of the

Arab J. Nucl. Sci. \& Applic. Vol. 52, No. 1 (2019) 
reinforcement of hard $\mathrm{GO}$ or $(\mathrm{ZnO})$ nanoparticles [57].

\section{Conclusions}

In this study, effect of GO nanoparticle weight percentage $(0.3 \mathrm{wt} \%)$ additions on microstructure, thermal behaviour and tensile properties of Sn$3.5 \mathrm{Ag}-0.7 \mathrm{Cu}$ solder alloy have been investigated. The conclusions summarized as follows:

1. The GO extension reinforces the UTS and the YS while the ductility decreased for ternary alloys. That growing in UTS and YS can be known owing to dispersion encouragement influence of crucify and finer IMCs as well as solid solution crucify of GO content. In extension, the growing in UTS with elevate $\varepsilon$. can be demonstrated by dislocations reduplication and dislocation junction. Therefore, the supplement of GO can crucify the

\section{References}

1- Suganuma. K. (2001) Advances in lead-free electronics soldering; Curr.Opin. Solid St. M. 5, 55-64.

2- Yong. Ma, Xuezheng. Li, Zhou. Wei, Lizhuang. Yang, Ping. Wu. (2017), Materials and Design, 113, 5, 264.

3- Chen G; Wu. F.S; Liu C.Q; Silberschmidtb. V.V., Chan. Y.C. (2016), Microstructures and properties of new $\mathrm{Sn}-\mathrm{Ag}-\mathrm{Cu}$ lead-free solder reinforced with $\mathrm{Ni}$-coated graphene nanosheets,. J. Alloys Compd. 656, 500-509.

4- Kanlayasiri. K., Ariga .T., (2015), Physical properties of Sn58Bi-xNi lead-free solder and its interfacial reaction with copper substrate, Mater. Des.86 371-378.

5- Yonekura. D., Ueki. T., Tokiyasu. K., Kira. S., Wakabayashi. T. (2015), Bonding mechanism of lead-fre e solder and glass plat e by ultrasonic assisted soldering method, Mater. Des. 65 907-913.

6- Roshanghias. Ali, Vrestal. Jan, Andriy Yakymovych, Klaus W. Richter, and Herbert Ipser. (2015). Sn-Ag-Cu nanosolders: Melting behavior and phase diagram prediction in the Sn-rich corner of the ternary system Calphad 49: 101,

7- Jiang. H,. Moon. K., Wong . C.P. Recent advances of nanolead-free solder material for low processing temperature interconnect applications solder matrix released significantly variable the stress exponent or activation energies.

2. It is index to be a susceptible parameter and treatment parameters of the samples of the ductility variation were generally large for the ternary plain alloy than composite alloys.

3. The UTS values of raised with rising strain rate and lowered with rising temperature. The ternary alloy had the small values of UTS and more elongation, and composite alloy has contrary value.

4. The supplement of GO into the ternary samples can growing the solder distinguishing, like the ultimate tensile strength (UTS), and diminish ductility. This is inasmuch the presence of intermetallic combination (IMCs) $\mathrm{Cu}_{3} \mathrm{Sn}$ and $\mathrm{Ag}_{3} \mathrm{Sn}$

5. The tensile parameters, the yield stress and the total elongation are highly influenced by temperature strain rate and.

(2013), Reliab 531968.

8- Pang. S., Yung. K. A Green Approach to Synthesis of Nanoparticles of $\mathrm{Sn}-3.0 \mathrm{Ag}-0.5 \mathrm{Cu}$ Lead-Free Solder Alloy Green Mater. Trans. 53. 1770, (2012).

9- Zou. C., Gao. Y., Yang. B., Zhai Q., (2012) Nanoparticles of $\mathrm{Sn} 3.0 \mathrm{Ag} 0.5 \mathrm{Cu}$ alloy synthesized at room temperature with large melting temperature depression.,J. Mater. Sci.: Mater. Electron 23, 2.

10- Yung K.C., Law C.M.T., Lee. C.P., Cheung, B., YueSize. T.M., (2012) Size Control and Characterization of $\mathrm{Sn}-\mathrm{Ag}-\mathrm{Cu}$ Lead-Free Nanosolders by a Chemical Reduction Process,J. Electron. Mater. 41, 313.

11- Gao.Y., Zou. C., Yang Bin, Zhai. Q., .Liu. J., .Zhuravlev. E., Schick C., (2009), Nanoparticles of $\mathrm{SnAgCu}$ lead-free solder alloy with an equivalent melting temperature of $\mathrm{SnPb}$ solder alloy

J. Alloy. Compd 484, 777.

12-Sun. J., Simon. S.L (2007), The melting behavior of aluminum nanoparticles, Acta. 463, 32.

13- Abtew M., Selvaduray G. (2000), Lead-free Solders in Microelectronics, Mater. Sci. Eng. R: Rep. 27; 95-141.

14- Sim. K., and Lee. J., (2014), Heat-induced spinodal decomposition of $\mathrm{Ag}-\mathrm{Cu}$ nanoparticles

J. Alloy. Compd. 590, 140. 
15- Lee J., Tanaka T., Lee J., Mori H. (2007), In situ atomic-scale observation of melting point suppression in nanometer-sized gold particles, Calphad. 31, 105.

16- Park J., Lee J. (2008), Phase diagram reassessment of $\mathrm{Ag}-\mathrm{Au}$ system including size effect, Calphad $32,135-141$.

17- Loomans M.E., Fine. M.E Metall. (2000), Tinsilver-copper eutectic temperature and composition

Mater. Trans. A. 31, 1155-1162.

18- Spinelli. J.E., Silva B.L., Garcia. A., (2014). Microstructure, phases morphologies and hardness of a $\mathrm{Bi}-\mathrm{Ag}$ eutectic alloy for high temperature soldering applications, Mater. Des. 58 482,

19- El-Daly.A.A., Desoky.W.M., Elmosalami.T.A., El-Shaarawy.M.G., Abdraboh. A.M (2015), Microstructural modifications and properties of SiC nanoparticles - reinforced $\mathrm{Sn}-3.0 \mathrm{Ag}$ $0.5 \mathrm{Cu}$ solder alloy, Mater. Des. 65, 11961204.

20- El-Daly. A.A., El-Taher. A.M., Dalloul. T.R. , (2014) Enhanced ductility and mechanical strength o f Ni-doped $\mathrm{Sn}-3.0 \mathrm{Ag}-0.5 \mathrm{Cu}$ lead-free solders, Mater. Des. 55, 309-318.

21- Shen L., Tan Z.Y., Chen. Z. , Nano indentation study on the creep resistance of $\mathrm{SnBi}$ solder alloy with reactive nano-metallic fillers, (2013), Mater. Sci. Eng. A 561 232-238.

22- Shen J., Pu. Y.Y., Yin H.G., Luo D.J., Chen J. (2014) Effects of minor $\mathrm{Cu}$ and $\mathrm{Zn}$ additions on the thermal, microstructure and tensile properties of Sn-Bi-based solder alloys J. Alloys Compd. 614; 63-70.

23- Yang L.Z., Zhou W., Liang. Cui. W.Q., Wu P., (2015) Improved microstructure and mechanica properties for Sn58Bi solder alloy by addition of $\mathrm{Ni}$-coated carbon nano tubes, Mater. Sci. Eng. A 642, 7-15.

24- Zhu Y.W., Murali. S., Cai W.W., Li. X.S., Suk J.W., Potts J.R., Ruoff R.S., (2010). Graphene and Graphene Oxide: Synthesis, Properties, and Applications, Adv. Mater. 223906.

25- Li. N., Wang Z.Y., Zhao. K.K., Shi Z.J., Gu. Z.N., Xu.S.K., (2010) Large scale synthesis of $\mathrm{N}$-doped multi-layered graphene sheets by simple arc-discharge method, Carbon 48 255,

26- Liu. M., Duan. Y., Wang Y., Zhao Y., (2014) Diazonium functionalization of graphene nanosheets and impact response of aniline modified graphene/bismaleimide nanocomposites, Mater. Des. 53, 466,

27- El-Daly A.A., El-Taher. A.M., (2013) Improved strength of $\mathrm{Ni}$ and $\mathrm{Zn}$-doped $\mathrm{Sn}$ 2.0Ag- $0.5 \mathrm{Cu}$ lead-free solder alloys under controlled processing parameters, Mater. Des. 47 607-614.

28- Xu. L., Wang. L., Jing. H., Liu. X., Wei. J., Han. Y., (2015) Effects of graphene nanosheets on interfacial reaction of $\mathrm{Sn}-$ Ag- $\mathrm{Cu}$ solder joints, J. Alloys Compd. 650, 475-481.

29- Xu L.Y., Zhang. Z.K., Jing. H.Y., Wei. J., Han. Y.D, (2015) Effect of graphene nanosheets on the corrosion behavior of $\mathrm{Sn}-\mathrm{Ag}-\mathrm{Cu}$ solders, J. Mater. Sci. Mater 26 5625-5634.

30- Hu. X., Chan Y.C, Zhang K., Yung. K.C, (2013) Effect of graphene doping on microstructural and mechanical properties of $\mathrm{Sn}-8 \mathrm{Zn}-3 \mathrm{Bi}$ solder joints together with electromigration analysis, J. Alloys Compd. 580 162-171.

31- Ma. D.L., Wu. P., (2016) Improved microstructure and mechanical properties for $\mathrm{Sn} 58 \mathrm{Bi} 0.7 \mathrm{Zn}$ solder joint by addition of graphene nanosheets, J. Alloys Compd. 671 127-131.

32- El-Daly.A.A., Hammad. A.E., (2012) Enhancement of creep resistance and thermal behavior of eutectic $\mathrm{Sn}-\mathrm{Cu}$ leadfree solder alloy by $\mathrm{Ag}$ and In-additions, Mater. Des. 40 292-298.

33- Peng.Y.T., Deng. K.,(2015) Study on the mechanical properties of the novel $\mathrm{Sn}-$ $\mathrm{Bi} / \mathrm{Graphene}$ nanocomposite by finite element simulation, J. Alloys Compd. 625 4451.

34- El-Daly A.A., Fawzy A., Mansour S.F., Younis M.J, Novel SiC nanoparticles-containing $\mathrm{Sn}-1.0 \mathrm{Ag}-0.5 \mathrm{Cu}$ solder with good drop impact performance. Mater Sci Eng A; 578, 62, (2013)

35- El-Daly A.A., Fawzy A., Mansour S.F., Younis M.J., 2013 Thermal analysis and mechanical properties of $\mathrm{Sn}-1.0 \mathrm{Ag}-0.5 \mathrm{Cu}$ solder alloy after modification with $\mathrm{SiC}$ nano-sized particles, J Mater Sci: Mater Electron 24; 2976-2988.

36- Fouda A.N., Eid E.A., (2015) Influence of $\mathrm{ZnO}$ nano-particles addition on thermal analysis, microstructure evolution and tensile behavior of $\mathrm{Sn}-5.0 \mathrm{wt} \% \mathrm{Sb}-$ $0.5 \mathrm{wt} \% \mathrm{Cu}$ lead-free solder alloy, Mater. Sci. Eng. A 632 82-87.

37- El-Daly A.A., Elmosalami T.A., Desoky W.M., El-Shaarawy M.G., Abdraboh A.M., (2014) Tensile deformation behavior and melting property of nano-sized $\mathrm{ZnO}$ particles reinforced $\mathrm{Sn}-3.0 \mathrm{Ag}-0.5 \mathrm{Cu}$ lead-free solder, Mater. Sci. Eng. A 618 389-396. 
38- Fawzy A., Fayek S.A., Sobhy M., Nassr E., Mousa M.M., Saad G., (2013). Effect of ZnO nanoparticles addition on thermal, microstructure and tensile properties of Sn-3.5 Ag-0.5 Cu (SAC355) solder alloy, J. Mater. Sci. Mater. Electron. 24 3210-3218.

39- Fawzy A., Fayek S.A., Sobhy M., E. Nassr, M.M. Mousa, G. Saad, (2014).Tensile creep characteristics of $\mathrm{Sn}-3.5 \mathrm{Ag}-0.5 \mathrm{Cu}$ (SAC355) solder reinforced with nanometric $\mathrm{ZnO}$ particles, Mater. Sci. Eng. A 603; 1-10.

40- Salem M.Y. (2016) Effects of $\mathrm{Cu}$ addition on creep characteristics of $\mathrm{Sn}-9 \mathrm{Zn}$ lead-free solders; Egypt. J. Solids, Vol. (39); 107-121.

41- Salem M.Y. (2017) Transient and steady-state creep characteristics of Transformations in AlZn Binary Alloys, International Journal of New Horizons in Physics Vol. 4, No. 2, 21-33.

42- Esfandyarpour M.J, Mahmudi R., (2011). Microstructure and tensile behavior of $\mathrm{Sn}-$ $5 \mathrm{Sb}$ lead-free solder alloy containing $\mathrm{Bi}$ and $\mathrm{Cu}$, Mater. Sci. Eng. A 530 402-410.

43- El-Daly A.A., A. Fawzy, A.Z. Mohamad, A.M. El-Taher, (2011). Microstructural evolution and tensile properties of $\mathrm{Sn}-5 \mathrm{Sb}$ solder alloy containing small amount of $\mathrm{Ag}$ and $\mathrm{Cu}$, J. Alloy. Compd. 509; 4574-4582.

44- Babaghorbani P., Nai S.M.L., Gupta M, (2009) Development of lead-free Sn3.5 Ag/SnO2 nanocomposite solders, J. Mater. Sci. Mater. Electron. 20; 571-576.

45- Shen J.. Chan Y.C, (2009) Effects of $\mathrm{ZrO} 2$ nanoparticles on the mechanical properties of $\mathrm{Sn}-\mathrm{Zn}$ solder joints on $\mathrm{Au} / \mathrm{Ni} / \mathrm{Cu}$ pads, J. Alloy. Compd. 477; 552559.

46- Fawzy. A. (2007) Effect of Zn addition, strain rate and deformation temperature on the tensile properties of $\mathrm{Sn}-3.3$ wt.\% $\mathrm{Ag}$ solder alloy Materials Characterization 58; 323-331.

47- Rodney J ., Mc Cabe. Fine M.E, (2002). Creep of tin, Sb-solution-strengthened tin, and SbSn-precipitate-strengthened tin, Metall. Mater. Trans. A33 (5); 1531-1539.
48- Rodney J ., Mc Cabe. Fine M.E, (2002), High creep resistance tin-based alloys for soldering applications

J. Electron. Mater. 31 (11) 1276-1282.

49- Humphreys F.J., Hatherly M., (2004) Recrystallization and Related Annealing Phenomena, ISBN: $0080441645 . \quad$ 2nd Edition, Elsevier Ltd. Oxford, UK, ISBN: , p. 114

50- Aghaie-Khafri.M (2004), Formability of AA8011 aluminum alloy sheet in homogenized and unhomogenized conditions, J. Mater. Sci. 39; 6467-6452.

51- Geranmayeha A.R., Mahmudi R., Kangooie M., (2011) High-temperature shearstrength of leadfree $\mathrm{Sn}-\mathrm{Sb}-\mathrm{Ag} / \mathrm{Al} 2 \mathrm{O} 3$ composite solder, Mater. Sci. Eng. A 528 3967-3972.

52- El-Daly AA, and Hammad. (2010) Elastic properties and thermal behavior of $\mathrm{Sn}-\mathrm{Zn}$ based lead-free solder alloys, J Alloys Comp;505:793-800.

53- Mahmudi R., Geranmayeh A.R., Khanbareh H., Jahangiri N., (2009) Design of lead-free candidate alloys for low-temperature soldering applications based on the hypoeutectic $\mathrm{Sn}-6.5$ Zn alloy, Mater. Des. 30; 574.

54- El Basatya A.B., Deghadyb A.M., Eidb E.A. (2017), Influence of small addition of antimony (Sb) on thermal behavior, microstructural and tensile properties of $\mathrm{Sn}-9.0 \mathrm{Zn}-0.5 \mathrm{Al} \mathrm{Pb}$-free solder alloy

Materials Science \& Engineering A 701; 245.

55- El-Daly A.A., Hammad A.E., Al-Ganainy G.A., and Ibrahiem A.A. (2013), Elastic properties and thermal behavior of $\mathrm{Sn}-\mathrm{Zn}$ based lead-free solder alloys Materials and Design 52 966-973.

56- Saad G., Fawzy A., Shawky E., (2009) Effect of $\mathrm{Ag}$ addition on the creep characteristics of $\mathrm{Sn}-8.8 \mathrm{wt} \% \mathrm{Zn}$ solder alloy, Journal of Alloys and Compounds 479, 844-850.

57- El-Daly A.A., Abdelhameed. M., Hashish M., Eid, A.M; (2012), Synthesis of $\mathrm{Al} / \mathrm{SiC}$ nanocomposite and evaluation of its mechanical properties using pulse echo overlap method, Journal of Alloys and Compounds 542, 51-58. 